\title{
Increased blood pressure variability predicts poor outcomes from endovascular treatment for aneurysmal subarachnoid hemorrhage
}

\author{
Aumento da variabilidade da pressão arterial prediz resultados ruins de tratamento \\ endovascular para hemorragia subaracnóide aneurismática
}

Xin-Bo GE'1, Qun-Fu YANG'1, Zhen-Bo LIU1', Tao ZHANG'1 , Chao LIANG ${ }^{1}$

\begin{abstract}
Background: Predictors of outcomes following endovascular treatment (ET) for aneurysmal subarachnoid hemorrhage (aSAH) are not welldefined. Identifying them would be beneficial in determining which patients might benefit from ET. Objective: To identify the predictive factors for poor outcomes following ET for aSAH. Methods: 120 patients with ruptured cerebral aneurysms underwent endovascular embolization between January 2017 and December 2018. Blood pressure variability was examined using the standard deviation of the 24-hour systolic blood pressure (24hSSD) and 24-hour diastolic blood pressure (24hDSD). Predictors were identified through univariate and multivariate regression analysis. All patients were followed up for three months. Results: At follow-up, 86 patients (71.7\%) had good outcomes and 34 (28.3\%) had poor outcomes. Patients with poor outcomes had significantly higher 24hSSD than those with good outcomes (19.3 \pm 5.5 vs $14.1 \pm 4.8 \mathrm{mmHg} ; \mathrm{P}<0.001)$. The 24hDSD did not differ significantly between patients with good outcomes and those with poor outcomes $(9.5 \pm 2.3$ vs $9.9 \pm 3.5 \mathrm{mmHg} ; \mathrm{P}=0.464)$. The following were significant risk factors for poor outcomes after endovascular embolization: age $\geq 65$ years (odds ratio $[\mathrm{OR}]=23.0 ; 95 \%$ confidence interval $[\mathrm{Cl}]: 3.0-175.9 ; \mathrm{P}=0.002)$; Hunt-Hess grade $3-4(\mathrm{OR}=6.8 ; 95 \% \mathrm{Cl}: 1.1-33.7 ; \mathrm{P}=$ 0.039); Fisher grade 3-4 (OR = 47.1; $95 \% \mathrm{Cl}: 3.8-586.5 ; \mathrm{P}=0.003)$; postoperative complications $(\mathrm{OR}=6.1 ; 95 \% \mathrm{Cl}: 1.1-34.8 ; \mathrm{P}=0.042)$; and $24 \mathrm{hSSD} \geq 15 \mathrm{mmHg}(\mathrm{OR}=14.9 ; 95 \% \mathrm{Cl}: 4.0-55.2 ; \mathrm{P}<0.001)$. Conclusion: Elevated $24 \mathrm{hSSD}$ is a possibly treatable predictive factor for poor outcomes after ET for aSAH.
\end{abstract}

Keywords: Hypertension; Aneurysm; Subarachnoid Hemorrhage; Endovascular Procedures.

\section{RESUMO}

Antecedentes: Fatores preditores de resultados após tratamento endovascular (TE) para hemorragia subaracnóide aneurismática (HSA) não estão bem definidos. Identificá-los seria útil para determinar quais pacientes podem se beneficiar de TE. Objetivo: Identificar os fatores preditivos de resultados ruins após TE para HSA. Métodos: 120 pacientes com aneurismas cerebrais rompidos foram submetidos à embolização endovascular entre janeiro de 2017 e dezembro de 2018. A variabilidade da pressão arterial foi examinada usando-se o desvio padrão da PA sistólica de 24 horas (DPPAS- 24h) e da PA diastólica de 24 horas (DPPAD-24h). Os fatores preditores foram identificados por meio de análises de regressão univariada e multivariada. Todos os pacientes foram acompanhados por três meses. Resultados: No acompanhamento, 86 pacientes $(71,7 \%)$ tiveram bons resultados e $34(28,3 \%)$ tiveram resultados ruins. Pacientes com resultados ruins apresentaram DPPAS-24h significativamente maior do que aqueles com bons resultados (19,3 $\pm 5,5 \mathrm{vs} 14,1 \pm 4,8 \mathrm{mmHg}$; $<$ <0,001). O DPPAD$24 \mathrm{~h}$ não diferiu significativamente entre os pacientes com bons resultados e aqueles com resultados ruins $(9,5 \pm 2,3 \mathrm{vs} 9,9 \pm 3,5 \mathrm{mmHg} ; \mathrm{P}=$ 0,464). Os fatores de risco significativos para resultados ruins após embolização endovascular foram os seguintes: idade $\geq 65$ anos (razão de probabilidade $[\mathrm{OR}]=23,0$; intervalo de confiança de 95\% [IC]:3,0-175,9; P = 0,002); escala de Hunt-Hess 3-4 (OR = 6,8; IC 95\%: 1,1-33,7; P = 0,039); escala de Fisher 3-4 (OR = 47,1; IC 95\%:3,8-586,5; P = 0,003); complicações pós-operatórias (OR = 6,1; IC 95\%: 1,1-34,8; P = 0,042); e DPPAS 24h $\geq 15$ mmHg (OR = 14,9; IC 95\%: 4,0-55,2; P <0,001). Conclusão: O DPPAS 24h elevado é um fator preditivo possivelmente tratável para resultados ruins após TE para HSA.

Palavras-chave: Hipertensão; Aneurisma; Hemorragia Subaracnóidea; Procedimentos Endovasculares.

'Xingtai People's Hospital, Department of Neurosurgery, Xingtai, Hebei 054001, China.

XBG (DD https://orcid.org/0000-0003-1310-3968; QFY (ID https://orcid.org/0000-0002-7965-6058;ZBL (iD https://orcid.org/0000-0002-5442-6897;

TZ (iD) https://orcid.org/0000-0003-0819-4316; CL (D) https://orcid.org/0000-0002-5899-7822

Correspondence:Xin-Bo Ge; Email: gexinbo_med@163.com.

Conflict of interest: There is no conflict of interest to declare.

Authors' contributions: XBG: wrote the manuscript; QFY, ZBL: collected the data; TZ, CL: analyzed the data. All authors contributed to editorial changes in the manuscript, read and approved the final manuscript.

Received on April 29, 2020; Received in its final form on December 3, 2020; Accepted on December 7, 2020. 


\section{INTRODUCTION}

Cerebral aneurysm is a local cystic swelling in the brain that is caused by a defect in the vascular wall. Its prevalence is around $3.6 \%-6 \%$, with a rupture rate of $1-2 \%$ in the population $^{1,2}$. Rupture of cerebral aneurysms is considered to be the second most common cause of subarachnoid hemorrhages (SAH), of which $20 \%-30 \%$ are serious cases ${ }^{3,4}$.

Endovascular embolization has been widely used for treating cerebral aneurysms. However, the prognostic factors for endovascular therapy outcomes in this population have not yet been clearly identified ${ }^{5}$. It has been shown that age, hypertension, intraoperative and postoperative complications, surgical timing and surgical methods are important factors affecting the prognosis for aneurysmal subarachnoid hemorrhage (aSAH). On the other hand, the impact of blood pressure fluctuations on the prognosis for aSAH is still unclear.

Therefore, we conducted the current investigation in an attempt to investigate the relationship between blood pressure variability and the prognosis for aSAH caused by cerebral aneurysm, following endovascular treatment.

\section{METHODS}

\section{Patients}

A total of 120 patients with ruptured cerebral aneurysms were prospectively enrolled between January 2017 and December 2018. We included all patients who presented ruptured cerebral aneurysm and aSAH, in line with the following inclusion criteria: (1) presenting with a clinical picture of aSAH; (2) having a computed tomography (CT) scan showing aSAH; and (3) having the presence of a ruptured cerebral aneurysm that was confirmed through CT angiography or digital subtraction angiography (DSA). Patients with the following conditions were excluded: negative results from the first head CT examination or lumbar puncture examination; secondary aSAH caused by vascular malformation, cerebral hemorrhage or trauma; no aneurysm identified through DSA; malignancies; severe diseases of the heart, lung, kidney or liver; or contraindications for endovascular treatment. In the same context, we also excluded patients who died within the first 24 hours of admission and patients whose blood pressure records within the first 24 hours were incomplete or unavailable. Our study was approved by the ethics committee of our hospital. All patients gave written informed consent prior to participating in our study.

\section{Surgical procedure}

All surgeries were performed under general anesthesia with tracheal intubation. Dual antiplatelet therapy in the form of aspirin (ASA) $300 \mathrm{mg}$ and clopidogrel $300 \mathrm{mg}$ was administered two hours before the surgery. The femoral artery was catheterized using the Seldinger method.
After systemic heparinization, aneurysms were embolized using an electrically detachable coil (Axium, Microvention, USA). Wide-necked aneurysms were embolized with a stent (Microvention, USA). In the case of multiple aneurysms, the culprit aneurysm was determined according to the hemorrhage location, the aneurysm and the presence of a pseudoaneurysm. Patients with stent-assisted embolization received oral clopidogrel $75 \mathrm{mg}$ daily for three months and aspirin 100 mg daily for six months.

Any occurrences of either intraoperative or postoperative complications during the study period were recorded, for all patients. The intraoperative complications included cerebral vasospasm, aneurysm rupture, thrombosis and apparatus-related complications. The postoperative complications included hydrocephalus, cerebral infarction and cerebral edema.

Hypertension needed to be induced within three hours following the initial presentation with clinical symptoms of delayed cerebral ischemia. Fluids and norepinephrine were used for inducing hypertension, through a central line positioned for this purpose in accordance with the local protocol of our center. This was maintained until one of the following conditions had been met: (1) improvement of neurological deficits; (2) occurrence of complications; (3) maximum mean arterial pressure of $130 \mathrm{mmHg}$; or (4) systolic blood pressure of $230 \mathrm{mmHg}$.

Occurrence of clinical improvement was judged by the treating surgeon. In cases with clinical improvement, norepinephrine was maintained for at least 48 hours and was then slowly tapered off. On the other hand, in cases of recurrence of symptoms during tapering, use of norepinephrine was restarted and tapering off was resumed after 24 hours. Meanwhile, norepinephrine was tapered off in the case of absence of clinical improvement.

\section{Blood pressure monitoring}

Ambulatory blood pressure was monitored for 24 hours after the endovascular treatment, using a dynamic blood pressure monitor (MCY-ABP1, Meigao, Beijing, China). The monitoring interval was every 30 minutes from 05:00 to 21:00 and every 60 minutes from 21:00 to 05:00. Blood pressure variability was defined as the standard deviation of the 24-hour systolic blood pressure (24hSSD), and that of the 24-hour diastolic blood pressure (24hDSD).

\section{Risk factors for treatment outcomes}

Risk factors for treatment outcomes and recurrence of aSAH were analyzed. These factors included sex, age, hypertension, diabetes, coronary artery disease, Hunt-Hess grade, Fisher grade, surgical timing ( $<3$ or $\geq 3$ days after the rupture), aneurysm diameter, aneurysm site, aneurysm neck $(>4$ or $<4 \mathrm{~mm}$ ), intraoperative complications and postoperative complications.

Transcranial Duplex ultrasonography examination was done twice daily, starting from the first 72 hours after disease 
onset, for the detection of cerebral vasospasm. Cerebral vasospasms were diagnosed through measurement of the mean flow velocity (MFV) of each of the middle, anterior and posterior cerebral arteries, and using the Lindegaard ratio (LR), i.e. the ratio of middle cerebral artery velocity to ipsilateral extracranial internal carotid artery velocity. In the same context, presence of vasospasm was identified through any of the following situations: (1) MFS of the posterior, anterior or middle cerebral artery rising above 60,90 or $120 \mathrm{~cm} / \mathrm{s}$, respectively; (2) MFV of the middle cerebral artery rising to more than $50 \mathrm{~cm} / \mathrm{s}$ above the first TCD assessment value; or (3) LR rising above three $e^{6,7}$. In addition, delayed cerebral ischemia was defined as follows: (1) presentation of focal neurological deficit/deterioration lasting for at least one hour; or (2) reduction in GCS $\geq 2$ points overall; and (3) after ruling out other causes that might lead to this neurological impairment, by means of clinical, laboratory and imaging studies. When more than one condition was identified, the decision regarding whether this clinical deterioration was attributable to delayed cerebral ischemia or not was made at the discretion of the operating surgeon ${ }^{8,9}$.

\section{Follow-up}

All the patients were followed up by telephone or through a visit to our clinic three months postoperatively. The outcomes were assessed using the modified Rankin scale: $0-2$ points for good outcomes and 3-6 points for poor outcomes.

\section{Statistical analysis}

Continuous data were presented as means and standard deviations (SD) and were compared using Student's t test. On the other hand, categorical data were presented as frequencies or percentages and were compared using the chi-square test. Univariate analysis was used to determine the possible risk factors predictive of poor outcomes from a ruptured cerebral aneurysm. Variables with $\mathrm{P}<0.20$ were included in the multivariate logistic regression analysis through a forward stepwise selection strategy. The $24 \mathrm{hSSD}$ and the $24 \mathrm{hDSD}$ were forced-in covariates in the final model. All statistical analyses were carried out using the Statistical Package for the Social Sciences (SPSS) 24.0 software (SPSS Inc., Chicago, IL, USA). P-values $<0.05$ were considered to be the cutoff point for statistical significance.

\section{RESULTS}

\section{Patients' demographic and clinical characteristics}

A total of 120 patients were included in the present study. There were 62 males and 58 females, and their ages ranged from 35 to 85 years. There was a history of essential hypertension in 74 patients $(61.7 \%)$ and diabetes in $12(10 \%)$. The diameter of the aneurysm was $<5 \mathrm{~mm}$ in 62 patients $(51.7 \%)$ and $\geq 5$ $\mathrm{mm}$ in 58 (48.3\%). Twenty-one patients (17.5\%) had multiple cerebral aneurysms. The time from admission to surgery was four days for 108 patients (90\%) and 4-14 days for 12 (10\%). At admission, the Hunt-Hess grade was 1-2 in 76 patients (63.3\%) and 3-4 in $44(36.7 \%)$. The Fisher grade was $1-2$ in $60(50 \%)$ patients and 3-4 in the other 60 (50\%).

\section{Treatment outcomes}

All the patients completed the three-month follow-up. Among them, 86 patients (71.7\%) had good outcomes and 34 (28.3\%) had poor outcomes. Complete embolization was achieved in 49 patients (40.8\%) and near-complete embolization was achieved in 71 (59.2\%). Intraoperative complications occurred in 39 patients (32.5\%) and postoperative complications occurred in 43 (35.8\%). The most common complication was intractable cerebral vasospasm $(71 / 120 ; 59.2 \%)$. The data on other complications are provided in Table 1.

\section{Results from risk factor analysis}

Univariate analysis showed that age $\geq 65$ years, intraoperative complications, postoperative complications, Hunt-Hess grade 3-4 and Fisher grade 3-4 were associated with poor outcomes (all with $\mathrm{P}<0.05$; Table 2 ).

The patients with poor outcomes had significantly higher 24hSSD than those with good outcomes $(19.3 \pm 5.5$ vs $14.1 \pm$ $4.8 \mathrm{mmHg}$; $<0.001)$. The $24 \mathrm{hDSD}$ did not significantly differ between patients with good outcomes and those with poor outcomes ( $9.5 \pm 2.3$ vs $9.9 \pm 3.5 \mathrm{mmHg}$; $\mathrm{P}=0.464$ ).

The medians of the 24hSSD and the 24hDSD were $15 \mathrm{mmHg}$ and $9 \mathrm{mmHg}$, respectively. In the logistic regression analysis, the outcome was used as the response variable; and age $\geq$ 65 years, Hunt-Hess grade 3-4, Fisher grade 3-4, postoperative complications, intraoperative complications, 24hSSD $\geq$ $15 \mathrm{mmHg}$ and $24 \mathrm{hDSD} \geq 9 \mathrm{mmHg}$ were used as the explanatory variables. The results showed that only five factors were

Table 1. Intraoperative and postoperative complications.

\begin{tabular}{lcc}
\hline Complications & $\begin{array}{c}\text { Good outcomes } \\
(\mathrm{n}, \%)\end{array}$ & $\begin{array}{c}\text { Poor outcomes } \\
(\mathrm{n}, \%)\end{array}$ \\
\hline Intraoperative complications & & $14(42.2)$ \\
\hline Cerebral vasospasm & $20(23.3)$ & $2(5.9)$ \\
\hline Aneurysm rupture & $1(1.2)$ & $1(2.9)$ \\
\hline $\begin{array}{l}\text { Thrombosis } \\
\text { Apparatus-related }\end{array}$ & $1(1.2)$ & $0(0.0)$ \\
\hline $\begin{array}{l}\text { Postoperative complications } \\
\text { Cerebral vasospasm }\end{array}$ & $0(0.0)$ & $15(44.1)$ \\
\hline Hydrocephalus & $22(25.6)$ & $0(0.0)$ \\
\hline Cerebral infarction & $1(1.2)$ & $1(2.9)$ \\
\hline Cerebral edema & $0(0.0)$ & $2(5.9)$ \\
\hline
\end{tabular}


significant risk factors/determinants for the outcome from endovascular therapy, namely: age $\geq 65$ years, Hunt-Hess grade $3-4$, Fisher grade $3-4$, postoperative complications and 24hSSD $\geq 15 \mathrm{mmHg}$ (Table 3).
With 'poor outcomes' as the dependent variable, the area under the receiver operating curve of the $24 \mathrm{hSSD}$ was 0.756 (P $<0.001$; Figure 1, Table 4). The best cutoff point for the receiver operating curve was $17.5 \mathrm{mmHg}$, with a sensitivity of $73.5 \%$ and a specificity of $80.2 \%$.

Table 2. Comparison of patients with good outcomes with those with poor outcomes.

\begin{tabular}{|c|c|c|c|c|}
\hline & & Good outcomes $(n=86)$ & Poor outcomes $(n=34)$ & $P$ \\
\hline \multirow{2}{*}{ Age (years) } & $<65$ years & $63(73.3)$ & $31(91.2)$ & \multirow{2}{*}{0.032} \\
\hline & $\geq 65$ years & $23(26.7)$ & $3(8.8)$ & \\
\hline \multirow{2}{*}{$\operatorname{Sex}(n, \%)$} & Male & $46(53.5)$ & $16(47.1)$ & \multirow{2}{*}{0.525} \\
\hline & Female & $40(46.5)$ & $18(52.9)$ & \\
\hline \multirow{2}{*}{ Diabetes (n, \%) } & Yes & $8(9.3)$ & $4(11.8)$ & \multirow{2}{*}{0.685} \\
\hline & No & $78(90.7)$ & $30(88.2)$ & \\
\hline \multirow{2}{*}{ Hypertension (n, \%) } & Yes & $50(58.1)$ & $24(70.6)$ & \multirow{2}{*}{0.206} \\
\hline & No & $36(41.9)$ & $10(29.4)$ & \\
\hline \multirow{2}{*}{ Coronary artery disease (n, \%) } & Yes & $42(48.8)$ & $17(50.0)$ & \multirow{2}{*}{0.909} \\
\hline & No & $44(51.2)$ & $17(50.0)$ & \\
\hline \multirow{2}{*}{ Intraoperative complications (n, \%) } & Yes & $22(25.6)$ & $17(50.0)$ & \multirow{2}{*}{0.01} \\
\hline & No & $64(74.4)$ & $17(50.0)$ & \\
\hline \multirow{2}{*}{ Postoperative complications (n, \%) } & Yes & $25(29.1)$ & $18(52.9)$ & \multirow{2}{*}{0.014} \\
\hline & No & $61(70.9)$ & $16(47.1)$ & \\
\hline \multirow{2}{*}{ Hunt-Hess grade (n, \%) } & $1-2$ & $61(70.9)$ & $15(44.1)$ & \multirow{2}{*}{0.006} \\
\hline & $3-4$ & $25(29.1)$ & $19(55.9)$ & \\
\hline \multirow{2}{*}{ Fisher grade (n, \%) } & $1-2$ & $62(72.1)$ & $14(41.2)$ & \multirow{2}{*}{0.002} \\
\hline & $3-4$ & $24(27.9)$ & $20(58.8)$ & \\
\hline \multirow{2}{*}{ Aneurysm diameter (n, \%) } & $<5 \mathrm{~mm}$ & $46(53.5)$ & $16(47.1)$ & \multirow{2}{*}{0.525} \\
\hline & $\geq 5 \mathrm{~mm}$ & $40(46.5)$ & $18(52.9)$ & \\
\hline \multirow{2}{*}{ Location of aneurysm (n, \%) } & Anterior circulation & $45(52.3)$ & $17(50.0)$ & \multirow{2}{*}{0.818} \\
\hline & Posterior circulation & $41(47.7)$ & $17(50.0)$ & \\
\hline \multirow{2}{*}{ Aneurysm neck (n, \%) } & Narrow & $48(55.8)$ & $19(55.9)$ & \multirow{2}{*}{0.995} \\
\hline & Wide & $38(44.2)$ & $15(44.1)$ & \\
\hline \multirow{2}{*}{ Surgical timing (n, \%) } & $<3$ days after the rupture & $78(90.7)$ & $30(88.2)$ & \multirow{2}{*}{0.688} \\
\hline & $\geq 3$ days after the rupture & $8(9.3)$ & $4(11.8)$ & \\
\hline
\end{tabular}

Table 3. Multivariate logistic regression analysis on the predictive factors for treatment outcomes from ruptured cerebral aneurysms.

\begin{tabular}{|c|c|c|c|c|c|c|c|}
\hline & \multirow{2}{*}{ B } & \multirow{2}{*}{ SE } & \multirow{2}{*}{ Wald } & \multirow{2}{*}{ Odds ratio } & \multicolumn{2}{|c|}{$95 \%$ confidence interval } & \multirow{2}{*}{$P$} \\
\hline & & & & & Lower limit & Upper limit & \\
\hline Age $\geq 65$ years & 3.143 & 1.034 & 9.226 & 23.108 & 3.046 & 175.294 & 0.002 \\
\hline Hunt-Hess grade $3-4$ & 1.913 & 0.918 & 4.123 & 6.773 & 1.143 & 33.675 & 0.039 \\
\hline Fisher grade 3-4 & 3.853 & 1.286 & 8.975 & 47.149 & 3.79 & 586.531 & 0.003 \\
\hline $\begin{array}{l}\text { Intraoperative } \\
\text { complications }\end{array}$ & 1.252 & 0.959 & 1.705 & 3.496 & 0.534 & 22.88 & 0.192 \\
\hline $\begin{array}{l}\text { Postoperative } \\
\text { complications }\end{array}$ & 1.807 & 0.889 & 4.132 & 6.093 & 1.067 & 34.812 & 0.042 \\
\hline $24 h S S D \geq 15 \mathrm{mmHg}$ & 2.699 & 0.671 & 16.256 & 14.871 & 4.004 & 55.238 & $<0.001$ \\
\hline $24 \mathrm{hDSD} \geq 9 \mathrm{mmHg}$ & -0.751 & 0.709 & 1.123 & 0.472 & 0.118 & 1.893 & 0.289 \\
\hline
\end{tabular}

24hSSD: 24-hour standard deviation of the systolic blood pressure; 24hDSD: 24-hour standard deviation of the diastolic blood pressure; SE: standard error; B: unstandardized beta. 


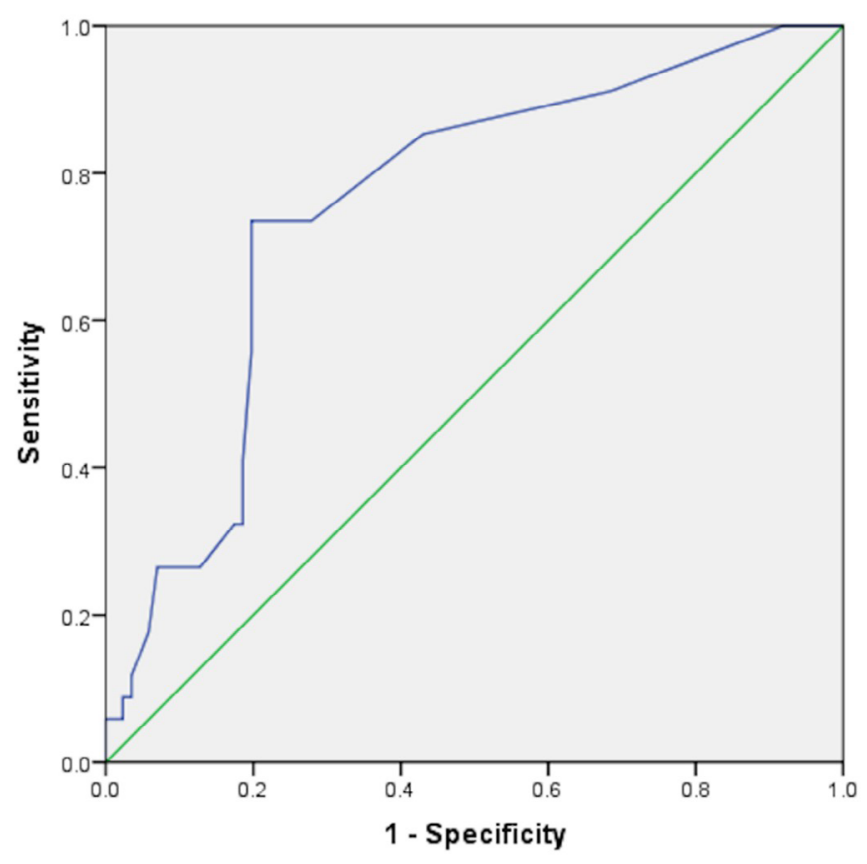

Figure 1. Receiver operating curve of the 24-hour standard deviation of the systolic blood pressure.

Table 4. Receiver operating curve distribution of the 24hSSD.

\begin{tabular}{|c|c|c|c|c|c|}
\hline & \multirow{2}{*}{$\begin{array}{c}\text { Area under } \\
\text { the receiver } \\
\text { operating curve }\end{array}$} & \multirow{2}{*}{ SE } & \multicolumn{2}{|c|}{$95 \%$ confidence interval } & \multirow{2}{*}{$P$} \\
\hline & & & Lower limit & Upper limit & \\
\hline 24hSSD & 0.756 & 0.048 & 0.662 & 0.85 & $<0.001$ \\
\hline
\end{tabular}

24hSSD: 24-hour standard deviation of the systolic blood pressure; SE: standard error.

\section{DISCUSSION}

Our study found that age $\geq 65$ years, Hunt-Hess grade $3-4$, Fisher grade $3-4$, postoperative complications and $24 \mathrm{hSSD} \geq 15$ $\mathrm{mmHg}$ were risk factors and determinants for poor outcomes after endovascular treatment for aSAH.

It has been shown that advanced age can adversely affect the prognosis for aSAH that is treated by endovascular therapy ${ }^{10}$. This effect may be due to the reduced tolerance of the aging cerebral vessels to the hemorrhagic injury, with associated complications. An increased Hunt-Hess grade at admission is also associated with poor prognosis for aSAH ${ }^{11}$. The HuntHess grade reflects the risks of cerebral vasospasm, aneurysm rebleeding and hydrocephalus ${ }^{12}$. Consistently with these previous data, our study found that Hunt-Hess grade 3-4 was an independent risk factor for poor outcomes from ruptured cerebral aneurysms treated with endovascular embolization. In addition, higher Fisher grades have also been associated with severe cerebral vasospasm and poor treatment outcomes for aSAH ${ }^{11,13}$. We confirmed this in our study, through showing that Fisher grade 3-4 was an independent risk factor for poor treatment outcomes for aSAH.
Our study showed that complications were independently associated with poor treatment outcomes from cerebral aneurysm rupture. About two-thirds of the patients with ruptured cerebral aneurysms develop refractory cerebral vasospasm when DSA is performed, and about $30 \%$ of these patients die from this complication. There is still no consensus on the treatment of postoperative refractory cerebral vasospasm among patients with cerebral aneurysm rupture ${ }^{14}$.

Our study found that 24hSSD was a risk factor for poor treatment outcomes for aSAH. However, hypertension and 24hDSD were not associated with poor treatment outcomes. Hypertension may increase the risk of cerebral aneurysm through vascular endothelial injury, derangement of elastic collagen synthesis and disturbance of vascular wall nutrition supply. Long-standing hypertension can lead to vascular damage such as intimal thickening, arteriosclerosis, extracellular matrix changes and degeneration of the elastic layer in blood vessels ${ }^{15}$. Blood pressure undergoes changes over periods of time and is regulated through neuroendocrine pathways ${ }^{16}$. It is considered to be an independent risk factor for stroke. It has been shown that reducing blood pressure variability improves the prognosis for stroke ${ }^{17,18}$.

Despite the recommendation from the European Stroke Organization that SBP in SAH should be maintained below 180 $\mathrm{mmHg}$ in order to minimize the risk of rebleeding in managing ruptured aneurysms ${ }^{19}$, no optimal BP thresholds have yet been determined, given the absence of evidence from randomized clinical trials ${ }^{20}$. Moreover, there is also wide variability regarding BP management targeted on treatment of ruptured intracerebral aneurysms. In our study, the main finding was that 24hSSD was significantly associated with poor clinical outcomes following endovascular treatment. This was in line with the observations of Xu et al. ${ }^{21}$, who reported that reduced SBP variability (successive variation, SV) was associated with favorable outcomes upon discharge. This suggests that maintaining the stability of the patient's BP would be more meaningful than just controlling the BP level after the endovascular embolectomy.

It has been observed that, in patients with intracerebral hemorrhage, their baroreflex sensitivity (as measured using a hemodynamic monitoring device) is reduced, with a concurrent increase in beat-to-beat BP variability ${ }^{22}$. In the same context, it is known that cerebral autoregulation is disrupted in patients with SAH, as seen through continuous observation of brain tissue oxygen pressure reactivity ${ }^{23}$ or via the phase shift angles $\left(\Delta \phi^{\circ}\right)$ between slow $(0.1 \mathrm{~Hz})$ arterial blood pressure and cerebral blood flow velocity waves, using transcranial US ${ }^{24}$.

This noticeable variation in BP could explain the autonomic dysfunction, including both the increase in sympathetic response and the reduction in baroreflex sensitivity. If autoregulation is substantially affected in situations of subarachnoid hemorrhage, cerebral flow becomes dependent on two parameters: cerebral perfusion pressure and blood velocity ${ }^{25}$. We found that during the first 24 hours after embolectomy, 
recovery from anesthesia following the double stress of the invasive intervention and the substantial damage caused by $\mathrm{SAH}$ was achieved. Thus, postoperative $\mathrm{BP}$ variability might be a precise indicator of the preserved potential for autoregulation in the body.

An elevation in systolic BP variability signifies that there is much less reserve capacity with regard to regulation of autonomic nervous function. Meanwhile, upon rupture of the aneurysm, the elevated systolic BP variability might increase the rate of acute aneurysmal rebleeding and accelerate further exacerbations ${ }^{26}$. In our study, the variation in the $24 \mathrm{hSSD}$ affected the clinical outcome of aSAH. Therefore, it is of great value to maintain $\mathrm{BP}$ stability throughout the entire period of management of aSAH.

In the presence of aSAH, blood enters the subarachnoid space, thus resulting in obstruction of cerebrospinal fluid outflow, acute hydrocephalus and increased intracranial pressure. This may lead to reduction of the brain's blood flow and brain perfusion pressure, which would lead to brain edema and cerebral ischemia. Increased blood pressure variability can cause either excessive or insufficient cerebral perfusion, and can aggravate ischemic cell cytotoxicity, reperfusion injury and ischemia-reperfusion expansion. It has been shown that higher blood pressure variability is associated with poor outcomes among patients with massive cerebral infarction ${ }^{27-29}$.

Our study had limitations. Firstly, blood pressure was only monitored for the first 24 hours postoperatively, which was shorter than the 72 hours in many previous studies. This may have resulted in relatively higher variation in the data. Secondly, our patients were from a single center and may have lacked representativeness.

In conclusion, $24 \mathrm{hSSD} \geq 15 \mathrm{mmHg}$ is a treatable risk factor for poor outcomes after endovascular treatment for aSAH. In addition to controlling hypertension, reducing blood pressure variability may also be considered to improve the outcomes relating to aSAH.

\section{REFERENCES}

1. Renowden SA, Benes V, Bradley M, Molyneux AJ. Detachable coil embolisation of ruptured intracranial aneurysms: a single center study, a decade experience. Clin Neurol Neurosurg. 2009 Feb;111(2):179-88. https://doi.org/10.1016/j.clineuro.2008.09.026

2. Vlak MH, Algra A, Brandenburg R, Rinkel GJ. Prevalence of unruptured intracranial aneurysms, with emphasis on sex, age, comorbidity, country, and time period: a systematic review and meta-analysis. Lancet Neurol. 2011 Jul;10(7):626-36. https://doi.org/10.1016/s14744422(11)70109-0

3. Komotar RJ, Schmidt JM, Starke RM, et al. Resuscitation and critical care of poor-grade subarachnoid hemorrhage. Neurosurgery. 2009 Mar;64(3):397-410; discussion 410-1. https://doi.org/10.1227/01. neu.0000338946.42939.c7

4. Rosengart AJ, Schultheiss KE, Tolentino J, Macdonald RL. Prognostic factors for outcome in patients with aneurysmal subarachnoid hemorrhage. Stroke. 2007 Aug;38(8):2315-21. https://doi.org/10.1161/ strokeaha.107.484360

5. Weir B, Aronyk K. Management and postoperative mortality related to time of clipping for supratentorial aneurysms: a personal series. Acta Neurochir (Wien). 1982;63(1-4):135-9.

6. Malhotra K, Conners JJ, Lee VH, Prabhakaran S. Relative changes in transcranial Doppler velocities are inferior to absolute thresholds in prediction of symptomatic vasospasm after subarachnoid hemorrhage.J Stroke Cerebrovasc Dis. 2014 Jan;23(1):31-6. https:// doi.org/10.1016/j.jstrokecerebrovasdis.2012.08.004

7. Sloan MA, Alexandrov AV, Tegeler CH, et al. Assessment: transcranial Doppler ultrasonography: report of the Therapeutics and Technology Assessment Subcommittee of the American Academy of Neurology. Neurology. 2004 May;62(9):1468-81. https://doi.org/10.1212/ wnl.62.9.1468

8. Vergouwen MD, Vermeulen M, van Gijn J, et al. Definition of delayed cerebral ischemia after aneurysmal subarachnoid hemorrhage as an outcome event in clinical trials and observational studies: proposal of a multidisciplinary research group. Stroke. 2010 Oct;41(10):2391-5. https://doi.org/10.1161/strokeaha.110.589275

9. Zafar SF, Westover MB, Gaspard N, et al. Interrater Agreement for Consensus Definitions of Delayed Ischemic Events After Aneurysmal Subarachnoid Hemorrhage. J Clin Neurophysiol. 2016 Jun;33(3):23540. https://doi.org/10.1097/wnp.0000000000000276
10. Jaja BN, Lingsma H, Steyerberg EW, Schweizer TA, Thorpe Macdonald $\mathrm{RL}$. Neuroimaging characteristics of ruptured aneurysm as predictors of outcome after aneurysmal subarachnoid hemorrhage: pooled analyses of the SAHIT cohort. J Neurosurg. 2016 Jun;124(6):1703-11. https://doi.org/10.3171/2015.4.jns142753

11. Zhang F, Li P, Zhang C, Wang L, Jing SQ. The Prognosis Factors for Endovascular Coiling of Aneurysm in Patients With Ruptured Intracranial Aneurysm. J Craniofac Surg. 2017 Sep 28;(6):e535-9. https://doi.org/10.1097/scs.0000000000003818

12. Li ZL, Zhang L, Ma XP, Liu W, Guo QD, Fei Z. Analysis of the timing and prognosis of interventionaltherapy for cerebral aneurysm rupture and hemorrhage. Chinese J Neurosurgical D Research. 2012;11(3):255-6. https://doi.org/cnki:sun:sjwk.0.2012-03-020

13. Duan G, Yang P, Li Q, et al. Prognosis Predicting Score for Endovascular Treatment of Aneurysmal Subarachnoid Hemorrhage: A Risk Modeling Study for Individual Elderly Patients. Medicine. 2016 Feb;95(7):e2686. https://doi.org/10.1097/md.0000000000002686

14. Barbarawi M, Smith SF, Jamous MA, Haboub H, Suhair Q, Abdullah S. Therapeutic approaches to cerebral vasospasm complicating ruptured aneurysm. Neurol Int. 2009 Nov 16;1(1):e13. https://doi. org/10.4081/ni.2009.e13

15. Inci S, Spetzler RF. Intracranial aneurysms and arterial hypertension: a review and hypothesis. Surg Neurol. 2000 Jun;53(6):530-40; discussion 540-532. https://doi.org/10.1016/s0090-3019(00)00244-5

16. Filomena J, Riba-Llena I, Vinyoles E, et al. Short-Term Blood Pressure Variability Relates to the Presence of Subclinical Brain Small Vessel Disease in Primary Hypertension. Hypertension. 2015 Sep;66(3):63440. https://doi.org/10.1161/hypertensionaha.115.05440

17. Rothwell PM, Howard SC, Dolan E, et al. Prognostic significance of visit-to-visit variability, maximum systolic blood pressure, and episodic hypertension. Lancet. 2010 Mar 13;375(9718):895-905. https://doi.org/10.1016/s0140-6736(10)60308-x

18. Cahan A, Ben-Dov IZ, Bursztyn M. Association of heart rate with blood pressure variability: implications for blood pressure measurement. Am J Hypertens. 2012 Mar;25(3):313-8. https://doi.org/10.1038/ ajh.2011.230

19. Steiner T, Juvela S, Unterberg A, Jung C, Forsting M, Rinkel G, European Stroke Organization guidelines for the management of intracranial aneurysms and subarachnoid haemorrhage. Cerebrovasc 
Dis. 2013;35(2):93-112. https://doi.org/10.1159/000346087

20. Carcel C, Sato S, Anderson CS. Blood pressure management in intracranial hemorrhage: current challenges and opportunities. Current treatment options in cardiovascular medicine. 2016 Apr;18(4):22. https://doi.org/10.1007/s11936-016-0444-z

21. Xu B, Ji Q, Zhang Y, Shen L, Cao M, Cai K. Postoperative blood pressure variability exerts an influence on clinical outcome after coil embolization of ruptured intracranial aneurysms. Neurol Res. 2017 Sep;39(9):813-8. https://doi.org/10.1080/01616412.2017.1348653

22. Sykora M, Diedler J, Rupp A, Turcani P, Rocco A, Steiner T. Impaired baroreflex sensitivity predicts outcome of acute intracerebral hemorrhage. Crir Care Med. 2008 Nov;36(11):3074-9. https://doi. org/10.1097/ccm.0b013e31818b306d

23. Jaeger M, Schuhmann MU, Soehle M, Nagel C, Meixensberger J. Continuous monitoring of cerebrovascular autoregulation after subarachnoid hemorrhage by brain tissue oxygen pressure reactivity and its relation to delayed cerebral infarction. Stroke. 2007 Mar;38(3):981-6. https://doi.org/10.1161/01. str.0000257964.65743.99

24. Lang EW, Diehl RR, Mehdorn HM. Cerebral autoregulation testing after aneurysmal subarachnoid hemorrhage: the phase relationship between arterial blood pressure and cerebral blood flow velocity. Crit
Care Med. 2001 Jan;29(1):158-63. https://doi.org/10.1097/00003246200101000-00031

25. Dankbaar JW, Slooter AJ, Rinkel GJ, Schaaf IC. Effect of different components of triple-H therapy on cerebral perfusion in patients with aneurysmal subarachnoid haemorrhage: a systematic review. Crit Care. 2010;14(1):R23. https://doi.org/10.1186/cc8886

26. Lin QS, Ping C, Lin YX, et al. Systolic Blood Pressure Variability is a Novel Risk Factor for Rebleeding in Acute Subarachnoid Hemorrhage: A Case-Control Study. Medicine (Baltimore). 2016 Mar;95(11):e3028. https://doi.org/10.1097/md.0000000000003028

27. Chung JW, Kim N, Kang J, et al. Blood pressure variability and the development of early neurological deterioration following acute ischemic stroke. J Hypertens. 2015 Oct;33(10):2099-2106. https://doi. org/10.1097/hjh.0000000000000675

28. de Havenon A, Bennett A, Stoddard GJ, et al. Determinants of the impact of blood pressure variability on neurological outcome after acute ischaemic stroke. Stroke Vasc Neurol. 2017 Feb 24;2(1):1-6. https://doi.org/10.1136/svn-2016-000057

29. Kang J, Ko Y, Park JH, et al. Effect of blood pressure on 3-month functional outcome in the subacute stage of ischemic stroke. Neurology. 2012 Nov 13;79(20):2018-24. https://doi.org/10.1212/ wnl.0b013e3182749eb8 